\title{
SINTESIS SURFAKTAN DIETANOLAMIDA (DEA) DARI METIL ESTER OLEIN SAWIT MENGGUNAKAN REAKTOR 25 LITER
}

\section{SYNTHESIS OF DIETHANOLAMIDE (DEA) SURFACTANT FROM PALM OLEIN METHYL ESTERS USING REACTOR 25 LITER}

\author{
Dora Vitra Meizar ${ }^{1}$, Ani Suryani ${ }^{2,3)^{*}}$,dan Erliza Hambali ${ }^{2,3)}$ \\ ${ }^{1)}$ Program Studi Teknologi Industri Pertanian, Fakultas Teknologi Pertanian, Institut Pertanian Bogor \\ Kampus IPB Darmaga, Bogor, Jawa Barat, Indonesia \\ ${ }^{2)}$ Departemen Teknologi Industri Pertanian, Fakultas Teknologi Pertanian, Institut Pertanian Bogor, Indonesia \\ E-mail: anisuryani.sbrcipb@gmail.com \\ ${ }^{3)}$ Surfactant and Bioenergy Research Center, LPPM-IPB
}

Makalah: Diterima 16 Agustus 2017; Diperbaiki 6 Oktober 2017; Disetujui 26 Oktober 2017

\begin{abstract}
Synthesis of diethanolamide (DEA) surfactant from palm olein methyl esters has the potential to commercialization. This surfactant product can reduce surface water tension from 72 dyne/cm to 33.82-32.06 dyne/cm in laboratory scale and the synthesis process was $50 \%$ cheaper than palm kernel fatty acids. So that, it is necessary to review the surfactant DEA production from palm olein methyl esters. The purpose of this research was to get the best synthesis process of DEA surfactant on 25 L/batch reactor. The synthesis process of DEA surfactants was divided into two stages. The first stage was conducted to determine duration and stirring rate of the DEA surfactant synthesis process. Then the best result in this first stage was continued in the second stage of the synthesis. The second stage was conducted by using an installed bulkhead in the reactor and some agitators for the DEA surfactant synthesis process. The lowest value of surface tension was the main parameter that was used for determining the best synthesis of DEA surfactant. Based on the first stage results, it was known that the best synthesis process was 4 hours with 100 rpm stirring rate. In the second stage, it was concluded that the best type of agitator was propeller. The best surface tension of DEA surfactant resulting from this research was 14.28 dyne $/ \mathrm{cm}$. The other parameters produced from the synthesis process were yield of $95.24 \%$, viscosity of $245.41 \mathrm{cP}$, density of $0.973 \mathrm{~g} / \mathrm{mL}$, and $\mathrm{pH}$ of 11.1 .
\end{abstract}

Key words : DEA surfactant, diethanolamide, surface tension, synthesis process

\section{ABSTRAK}

Sintesis surfaktan dietanolamida (DEA) dari metil ester olein sawit berpotensi untuk dikomersialkan. Produk surfaktan ini mampu menurunkan tegangan permukaan air dari 72 dyne/cm menjadi 33,82 - 32,06 dyne/cm pada skala laboratorium dan proses sintesisnya 50\% lebih murah dibandingkan asam lemak inti sawit sehingga perlu dilakukan pengkajian produksi surfaktan DEA dari metil ester olein sawit. Tujuan dari penelitian ini adalah untuk mendapatkan proses sintesis surfaktan DEA terbaik pada reaktor $25 \mathrm{~L} /$ batch. Proses sintesis surfaktan DEA dibagi menjadi dua tahapan. Tahap pertama menentukan lama proses dan kecepatan pengadukan sintesis surfaktan DEA. Hasil terbaik pada tahap pertama akan dilanjutkan pada sintesis tahap kedua. Tahap kedua dilakukan pemasangan sekat pada reaktor dan penentuan jenis pengaduk yang digunakan untuk sintesis surfaktan DEA. Nilai tegangan permukaan terendah merupakan parameter utama dalam menentukan sintesis surfaktan DEA terbaik. Berdasarkan hasil penelitian sintesis tahap pertama didapatkan lama proses sintesis terbaik adalah 4 jam dengan kecepatan pengadukan $100 \mathrm{rpm}$. Pada tahap kedua didapatkan jenis pengaduk terbaik adalah pengaduk propeller. Tegangan permukaan surfaktan DEA yang dihasilkan adalah 14,28 dyne/cm. Parameter lainnya dari proses sintesis tersebut adalah rendemen 95,24\%, viskositas $245,41 \mathrm{cP}$, densitas 0,973 $\mathrm{g} / \mathrm{mL}$ dan nilai $\mathrm{pH} 11,1$.

Kata kunci : Dietanolamida, proses sintesis, surfaktan DEA,tegangan permukaan

\section{PENDAHULUAN}

Surfaktan merupakan senyawa aktif dalam menurunkan tegangan permukaan karena memiliki gugus hidrofilik dan hidrofobik. Secara umum surfaktan dibagi menjadi 4 kelompok yaitu 1) surfaktan anionik, 2) surfaktan kationik, 3) surfaktan nonionik, dan 4) surfaktan amphoterik. Surfaktan yang bersumber dari bahan baku minyak nabati berpotensi untuk dikembangkan karena dapat diperbaharui dan ramah lingkungan. Salah satu jenis surfaktan yang banyak digunakan dalam industri adalah surfaktan DEA. Surfaktan DEA merupakan kelompok surfaktan nonionik yang dapat diperoleh dari proses amidasi menggunakan metil ester ataupun asam lemak (Hambali et al., 2013). Surfaktan DEA banyak digunakan sebagai bahan tambahan dalam membuat suatu produk. Salah satunya diaplikasikan pada pembuatan sabun transparan (Hambali et al., 2005). 
Pada penelitian sintesis surfaktan DEA dari metil ester olein sawit menunjukkan bahwa DEA yang diproduksikan mampu menurunkan tegangan permukaan air dari 72 dyne/cm menjadi 33,82 dyne/cm sampai 32,06 dyne/cm pada skala laboratorium. Hal ini menunjukkan bahwa penambahan DEA metil ester olein sawit mampu menurunkan tegangan permukaan sekitar $53-55 \%$ (Hambali et al., 2013). Parameter tegangan permukaan air ini sangat berpengaruh terhadap sistem emulsi suatu larutan. Semakin kecil nilai tegangan permukaan air akan membuat sistem emulsi suatu larutan semakin stabil dan membuat larutan tersebut semakin mudah bercampur dengan air (Susanto, 2007). Produk sintesis surfaktan DEA dari metil ester olein sawit diperkirakan $50 \%$ lebih murah dibandingkan asam lemak inti sawit (Hambali et al., 2013), sehingga hal ini sangat berpotensi untuk dikomersialkan.

Produksi surfaktan DEA pada penelitian ini menggunakan reaktor skala 25 L/batch. Penggunaan reaktor ini merupakan tahapan kedua dalam pengembangan produk surfaktan DEA kedalam skala industri. Dalam proses pembuatan surfaktan DEA, lama reaksi antara pereaksi mempengaruhi banyaknya produk yang dihasilkan, semakin banyak produk yang dihasilkan maka kinerja surfaktan juga semakin meningkat. Selain lama reaksi, kecepatan pengadukan dalam proses produksi surfaktan DEA juga perlu diperhatikan. Kecepatan pengadukan memberikan perataan panas pada seluruh bagian campuran didalam reaktor sehingga mempengaruhi jumlah energi aktivasi pereaksi untuk berinteraksi antarmuka pereaksi (Hasenhuetti, 2000).

Lama proses dan kecepatan pengadukan yang tepat diharapkan akan menghasilkan surfaktan DEA yang memiliki karakteristik dan kinerja terbaik. Faktor lainnya yang perlu diperhatikan dalam proses produksi surfaktan DEA pada reaktor $25 \mathrm{~L}$ adalah jenis pengaduk. Kekentalan cairan yang akan diaduk akan menentukan jenis/ tipe pengaduk. Pengaduk dengan tipe propeller digunakan untuk cairan dengan viskositas dibawah $3.000 \mathrm{cp}$, tipe pengaduk turbin umumnya digunakan untuk mengaduk cairan dengan kekentalan dibawah
$100.000 \mathrm{cp}$, tipe paddle seperti model jangkar digunakan untuk mengaduk cairan dengan viskositas 50.000-500.000 cp, tipe helical dan ribbon digunakan untuk cairan dengan viskositas diatas 25.000.000 cp (Geankoplis, 2003). Surfaktan DEA memiliki viskositas yang rendah oleh karena itu jenis pengaduk yang digunakan pada penelitian ini adalah propeller dan juga turbin.

Penelitian ini bertujuan untuk mendapatkan kondisi proses terbaik yang digunakan untuk produksi surfaktan DEA dari metil ester olein sawit menggunakan reaktor skala 25 L/batch dan memperoleh karakteristik produk surfaktan DEA dari metil ester olein sawit yang dihasilkan.

\section{BAHAN DAN METODE}

\section{Bahan dan Alat}

Bahan yang digunakan adalah metil ester hasil produksi di SBRC, dietanolamina dari Gratama Chemical, surfaktan DEA hasil penelitian, $\mathrm{NaOH}$, air dan bahan lainnya yang dibutuhkan dalam analisis. Peralatan yang digunakan dalam penelitian meliputi reaktor amidasi skala $25 \mathrm{~L}$, pengukur tegangan permukaan (Spinning Drop Tensiometer), density meter (Densitymeter Anton Paar DMA 4500M), viscometer (Rheometer Brookfield DV-III Ultra), timbangan, Erlenmeyer, thermometer, gelas ukur, gelas piala.

\section{Tahapan Penelitian}

Adapun tahapan yang dilakukan dalam penelitian ini adalah sebagai berikut :

Pengaruh Lama Proses Sintesis Dan Kecepatan Pengadukan Pada Proses Produksi Surfaktan DEA

Pada tahapan ini, sintesis surfaktan DEA menggunakan metode Hambali et al. (2013) yang dimodifikasi. Proses produksi surfaktan DEA pada tahap ini dilakukan untuk melihat pengaruh lama proses sintesis dan kecepatan pengadukan proses produksi surfaktan DEA. Diagram alir proses produksi surfaktan DEA dapat dilihat pada Gambar 1.

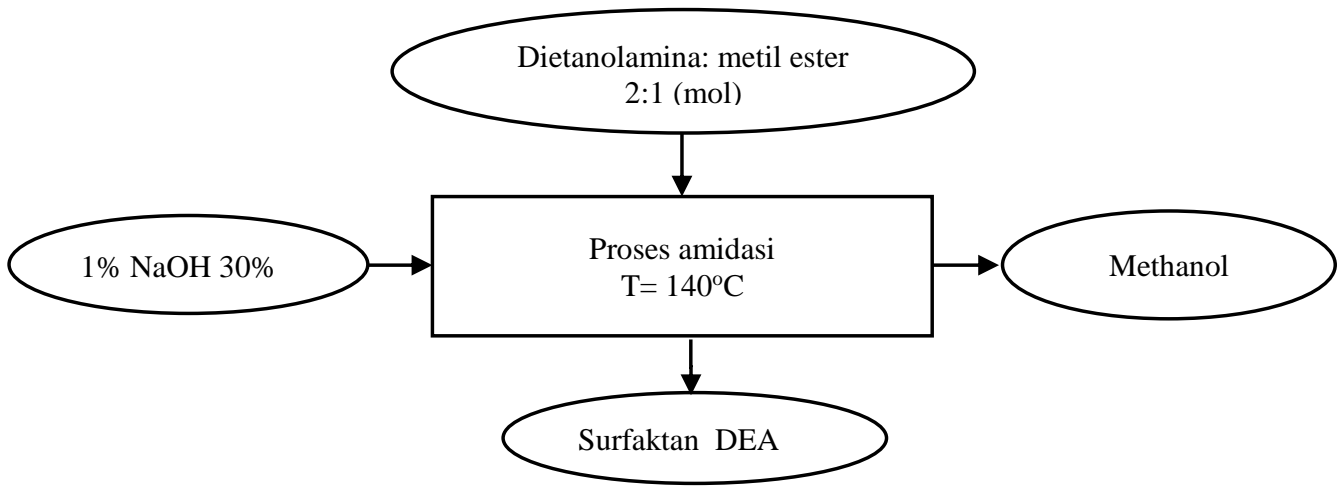

Gambar 1. Proses sintesis surfaktan DEA pada perlakuan lama proses dan kecepatan pengadukan (modifikasi Hambali et al., 2013) 
Sintesis dilakukan dengan mereaksikan dietanolamina dan metil ester olein sawit dengan perbandingan 2:1 mol kedalam reaktor selanjutnya dilakukan penambahan konsentrasi katalis $\mathrm{NaOH}$ $30 \%$ sebanyak $1 \%$ dari total bahan dietanolamina dan metil ester yang digunakan. Proses reaksi dilakukan pada suhu $140^{\circ} \mathrm{C}$ dengan berbagai perlakuan lama reaksi dan juga perlakuan kecepatan pengadukan. Proses dalam reaktor ini akan menghasilkan produk utama yaitu surfaktan DEA dan juga hasil samping berupa methanol.

Perlakuan tahap pertama adalah menganalisis pengaruh lama proses dan kecepatan pengadukan surfaktan DEA. Pada skala laboratorium lama proses sintesis surfaktan DEA yang digunakan adalah 4 jam. Lama proses sintesis surfaktan DEA pada tahap 1 ini dibagi menjadi 3 taraf perlakuan yaitu 3 jam, 4 jam dan 5 jam. Tujuannya adalah untuk menganalisis pengaruh lama proses sintesis terhadap kualitas surfaktan DEA yang dihasilkan. Pengaruh kecepatan pengadukan sintesis surfaktan DEA dibagi menjadi 2 taraf perlakuan yaitu $100 \mathrm{rpm}$ dan $200 \mathrm{rpm}$. Tujuannya adalah untuk menganalisis kemampuan pengadukan dan pengaruhnya terhadap surfaktan DEA yang dihasilkan. Pemilihan kecepatan pengadukan didasarkan pada kecepatan maksimal alat produksi surfaktan DEA yaitu 200 rpm dan menganalisis juga proses produksinya pada setengah kecepatan maksimum alat yaitu $100 \mathrm{rpm}$. Rancangan percobaan yang digunakan dalam penelitian ini adalah rancangan acak lengkap dua faktorial. Model matematika yang digunakan adalah:

$$
Y_{i j k}=\mu+A_{i}+B_{j}+(A B)_{i j}+E_{i j k}
$$

Keterangan:

\begin{tabular}{|c|c|c|}
\hline$Y_{i j k}$ & $=$ & Hasil pengamatan \\
\hline$\mu$ & $=$ & Nilai rataan umum \\
\hline$A_{i}$ & $=$ & $\begin{array}{l}\text { Pengaruh lama proses produksi } \\
\text { surfaktan DEA taraf ke-i }(3,4 \text { dan } 5 \\
\text { jam) }\end{array}$ \\
\hline$B_{j}$ & $=$ & $\begin{array}{l}\text { Pengaruh kecepatan pengadukan } \\
\text { proses produksi surfaktan DEA taraf } \\
\text { ke-j }(100 \text { dan } 200 \mathrm{rpm})\end{array}$ \\
\hline$A B_{i j}$ & $=$ & $\begin{array}{l}\text { Interaksi antara pengaruh lama proses } \\
\text { produksi surfaktan DEA taraf ke-i dan } \\
\text { kecepatan pengadukan proses produksi } \\
\text { surfaktan DEA taraf ke-j }\end{array}$ \\
\hline$E_{i j k}$ & & Galat percobaan \\
\hline
\end{tabular}

Pemilihan lama proses dan kecepatan pengadukan terbaik pada sintesis surfaktan DEA ditentukan dari sifat fisiko kimia surfaktan DEA yang dianalisis. Parameter analisis surfaktan DEA yang dilakukan meliputi rendemen, tegangan permukaan, densitas, viskositas dan pengujian $\mathrm{pH}$.

\section{Pemilihan Jenis Pengaduk Pada Proses Produksi Surfaktan DEA}

Pada proses sintesis surfaktan DEA tahap ini dilakukan pemasangan baffle pada reaktor untuk mencegah terjadinya cekungan pada tangki (vortex). Pada fluida yang memiliki viskositas rendah, pengadukan yang tinggi dapat menyebabkan terbentuknya vortex (cekungan permukaan media pada bagian tengah tangki) sehingga menyebabkan pencampuran tidak dapat berlangsung dengan baik. Proses sintesis surfaktan DEA terbaik pada perlakuan lama proses dan kecepatan pengadukan akan digunakan untuk analisis jenis pengaduk pada sintesis surfaktan DEA selanjutnya.

Faktor jenis pengaduk pada proses sintesis surfaktan DEA menggunakan 2 taraf perlakuan, yaitu jenis pengaduk propeller dan turbin. Rancangan percobaan yang digunakan dalam penelitian ini adalah rancangan acak lengkap satu faktorial. Model matematika yang digunakan adalah:

$$
Y_{i j}=\mu+C_{i}+E_{i j}
$$

Keterangan :

$$
\begin{aligned}
c & =\text { Hasil pengamatan } \\
\mu & =\text { Nilai rataan umum } \\
C_{i} & =\text { Pengaruh jenis pengaduk taraf ke-i } \\
& \text { (pengaduk propeller dan turbin) } \\
E_{i j}= & \text { Galat percobaan }
\end{aligned}
$$

Pemilihan jenis pengaduk terbaik pada proses sintesis surfaktan DEA ditentukan dari sifat fisiko kimia surfaktan DEA yang dihasilkan. Parameter analisis surfaktan DEA yang dilakukan meliputi rendemen, tegangan permukaan, densitas, viskositas dan pengujian $\mathrm{pH}$.

\section{HASIL DAN PEMBAHASAN}

\section{Pengaruh Lama Proses dan Kecepatan Pengadukan Produksi Surfaktan DEA}

Dalam proses sintesis surfaktan DEA, proses pengadukan merupakan salah satu faktor yang perlu diperhatikan. Pengadukan merupakan operasi yang menciptakan terjadinya gerakan dari bahan yang diaduk seperti molekul, zat atau komponen yang bergerak dan menyebar (terdispersi). Tujuan dilakukannya proses pengadukan didalam proses sintesis surfaktan DEA adalah untuk menghomogenkan produk sehingga diperoleh pencampuran yang tinggi dengan lama proses pencampuran yang singkat dan juga konsumsi energi yang rendah. Produk hasil dari proses reaksi amidasi akan mulai terbentuk pada lama proses 1 jam dan akan meningkat terus menerus dan akan maksimal pada lama proses 4 jam.

Pada penelitian ini lama proses yang digunakan untuk sintesis surfaktan DEA adalah 3, 4 dan 5 jam, sedangkan kecepatan pengadukannya adalah $100 \mathrm{rpm}$ dan $200 \mathrm{rpm}$. Surfaktan DEA yang dihasilkan berupa cairan. Namun selama penyimpanan, produk tersebut akan mengalami perubahan menjadi padat. Jika produk akan dianalisis dan digunakan kembali, maka dilakukan 
pemanasan pada suhu $40^{\circ} \mathrm{C}$ sehingga surfaktan DEA akan mencair dan siap untuk digunakan kembali.

\section{Rendemen}

Rendemen merupakan salah satu faktor penting dalam menentukan proses sintesis surfaktan DEA. Rendemen adalah hasil produksi dibandingkan dengan bahan awal yang digunakan dalam proses sintesis surfaktan DEA. Rendemen yang tinggi menjadi salah satu faktor dalam pemilihan proses sintesis surfaktan DEA. Perbedaan lama proses sintesis terhadap rendemen surfaktan DEA yang dihasilkan disajikan pada Gambar 2.

Hasil analisis ragam menunjukkan bahwa lama proses sintesis surfaktan DEA yang berbeda memberikan pengaruh yang nyata terhadap rendemen surfaktan DEA. Sedangkan perbedaan kecepatan pengadukan maupun interaksi antara lama proses sintesis surfaktan DEA dengan kecepatan pengadukan tidak memberikan pengaruh yang nyata terhadap rendemen surfaktan DEA. Rendemen yang dihasilkan berdasarkan perbedaan lama proses sintesis DEA berkisar antara 94,62 $\pm 0,57 \%$ sampai $95,45 \pm 0,14 \%$. Rendemen tertinggi didapat pada surfaktan DEA dengan lama proses sintesis 4 jam. Ini menunjukkan lama proses paling efektif untuk proses sintesis dalam menghasilkan produk surfaktan DEA adalah selama 4 jam. Menurut Susanto (2007) lama proses reaksi dipengaruhi oleh karakteristik pereaksi danproduk dan juga kondisi dari rekasi yang dijalankan.

Surfaktan DEA yang dihasilkan sangat ditentukan oleh reaksi kimia yang terjadi antara metil ester dan dietanolamina. Lama proses sintesis akan mempengaruhi jumlah DEA yang akan terbentuk. Semakin lama interaksi antara pereaksi maka akan menghasilkan produk yang semakin banyak pula namun proses ini akan konstan pada waktu reaksi tertentu (Susanto, 2007). Ini ditunjukkan oleh rendemen produksi surfaktan DEA dengan lama proses 4 jam tidak berbeda signifikan dengan lama proses 5 jam. Proses pengadukan akan mempercepat kecepatan reaksi karena luas permukaan bidang sentuh antara pereaksi akan bertambah dengan proses pengadukan. Rendemen yang dihitung pada penelitian ini adalah rendemen keselurahan produk (crude DEA). Produk DEA yang dihasilkan pada penelitian ini mengandung dietanolamida, sisa dietanolamina dan juga mengandung $\mathrm{NaOH}$. Hasil analisis ragam menunjukkan bahwa lama proses sintesis surfaktan DEA yang berbeda memberikan pengaruh yang nyata terhadap rendemen surfaktan DEA. Sedangkan perbedaan kecepatan pengadukan maupun interaksi antara lama proses sintesis surfaktan DEA dengan kecepatan pengadukan tidak memberikan pengaruh yang nyata terhadap rendemen surfaktan DEA. Rendemen yang dihasilkan berdasarkan perbedaan lama proses sintesis DEA berkisar antara 94,62 \pm $0,57 \%$ sampai $95,45 \pm 0,14 \%$. Rendemen tertinggi didapat pada surfaktan DEA dengan lama proses sintesis 4 jam. Ini menunjukkan lama proses paling efektif untuk proses sintesis dalam menghasilkan produk surfaktan DEA adalah selama 4 jam. Menurut Susanto (2007) lama proses reaksi dipengaruhi oleh karakteristik pereaksi danproduk dan juga kondisi dari rekasi yang dijalankan.

Surfaktan DEA yang dihasilkan sangat ditentukan oleh reaksi kimia yang terjadi antara metil ester dan dietanolamina. Lama proses sintesis akan mempengaruhi jumlah DEA yang akan terbentuk. Semakin lama interaksi antara pereaksi maka akan menghasilkan produk yang semakin banyak pula namun proses ini akan konstan pada waktu reaksi tertentu (Susanto, 2007). Ini ditunjukkan oleh rendemen produksi surfaktan DEA dengan lama proses 4 jam tidak berbeda signifikan dengan lama proses 5 jam. Proses pengadukan akan mempercepat kecepatan reaksi karena luas permukaan bidang sentuh antara pereaksi akan bertambah dengan proses pengadukan. Rendemen yang dihitung pada penelitian ini adalah rendemen keselurahan produk (crude DEA). Produk DEA yang dihasilkan pada penelitian ini mengandung dietanolamida, sisa dietanolamina dan juga mengandung $\mathrm{NaOH}$.

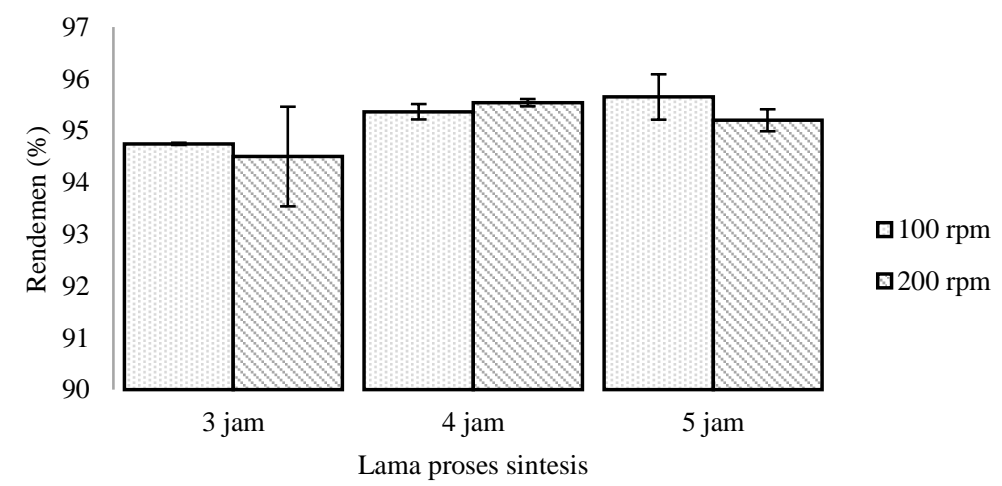

Gambar 2. Pengaruh lama proses sintesis terhadap rendemen surfaktan DEA yang dihasilka 


\section{Tegangan Permukaan}

Tegangan permukaan air sesudah penambahan surfaktan DEA yang dihasilkan menjadi indikator utama dalam pemilihan lama proses dan kecepatan pengadukan sintesis surfaktan DEA. Tegangan permukaan terkecil yang dihasilkan akan menjadi proses yang terpilih. Surfaktan DEA cenderung larut didalam air dan selanjutnya akan berperan sebagai emulsifier dengan melapisi dinding-dinding globula. Surfaktan DEA memiliki kemampuan dalam menurunkan tegangan permukaan dengan melapisi globula, ukuran globula yang kecil dan seragam akan meningkatkan kemampuan surfaktan DEA untuk melapisi sehingga kemampuannya dalam menurunkan tegangan permukaan dapat berlangsung dengan maksimal (Ferdinan et al., 2016). Nilai tegangan permukaan air setelah penambahan surfaktan DEA dengan berbagai perlakuan disajikan pada Gambar 3 .

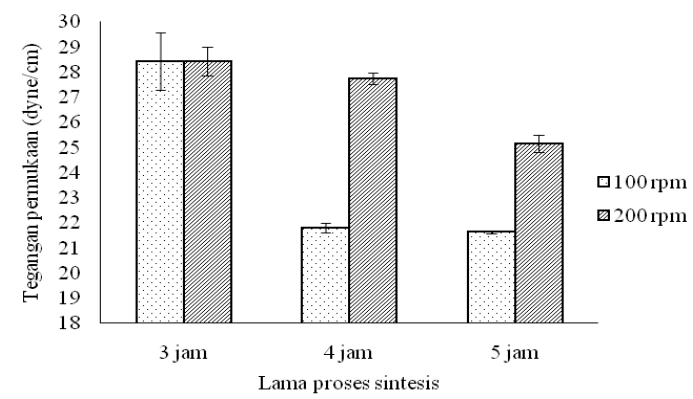

Gambar 3. Grafik hubungan lama proses sintesis pada berbagai tingkat kecepatan pengadukan terhadap tegangan permukaan surfaktan DEA

Hasil analisis ragam menunjukkan bahwa lama proses dan kecepatan pengadukan serta interaksi keduanya memberikan pengaruh yang nyata pada taraf $5 \%$ terhadap nilai tegangan permukaan surfaktan DEA yang dihasilkan. Proses sintesis surfaktan DEA dengan lama proses 5 jam dengan kecepatan pengadukan $100 \mathrm{rpm}$ menghasilkan tegangan permukaan lebih rendah, namun secara uji statistik 5 jam dan 4 jam dengan kecepatan pengadukan $100 \mathrm{rpm}$ tidak berbeda nyata pada taraf 5\%. Oleh karena itu proses terbaik yang dipilih adalah proses sintesis DEA dengan lama proses 4 jam dan kecepatan pengadukan $100 \mathrm{rpm}$ karena lama proses sintesisnya lebih cepat dan menghasilkan nilai tegangan permukaan yang tidak berbeda nyata dengan lama proses 5 jam. Lama proses 4 jam dengan kecepatan $100 \mathrm{rpm}$ menghasilkan tegangan permukaan sebesar 21,80 \pm 0,19 dyne $/ \mathrm{cm}$. Nilai tegangan permukaan air sebelum penambahan surfaktan DEA adalah 72 dyne/cm. Nilai tegangan permukaan air setelah penambahan surfaktan DEA 2\% menjadi antara 28,44-21,64 dyne/cm. Ini menunjukkan bahwa penambahan surfaktan DEA pada konsentrasi tertentu dalam air akan menurunkan nilai tegangan permukaan air. Semakin kecil nilai tegangan permukaan maka akan membuat emulsi suatu larutan semakin stabil dan campuran suatu larutan semakin homogen.

Lama proses dan kecepatan pengadukan erat hubungannya dalam meningkatkan reaksi amidasi dalam proses produksi surfaktan DEA. Lama proses meningkatkan jumlah produksi surfaktan DEA sedangkan kecepatan pengadukan meningkatkan reaksi antara metil ester dan dietanolamina sehingga reaksi akan berlangsung lebih cepat. Dengan meningkatnya lama proses dan kecepatan pengadukan akan memperbanyak jumlah dietanolamina yang terikat membentuk surfaktan DEA sehingga akan semakin meningkat nilai penurunan tegangan permukaan air. Namun jumlah surfaktan DEA tertentu akan menghasilkan penurunan tegangan permukaan akan sama.

\section{Viskositas}

Viskositas merupakan salah satu sifat fluida yang dipengaruhi oleh ukuran molekul dan gaya antar molekul. Viskositas menunjukkan ketahanan mengalir suatu fluida. Bahan yang sulit untuk dialirkan memiliki viskositas yang tinggi sedangkan fluida yang mudah mengalir memiliki viskositas yang rendah. Hasil pengujian viskositas surfaktan DEA disajikan pada Gambar 4.

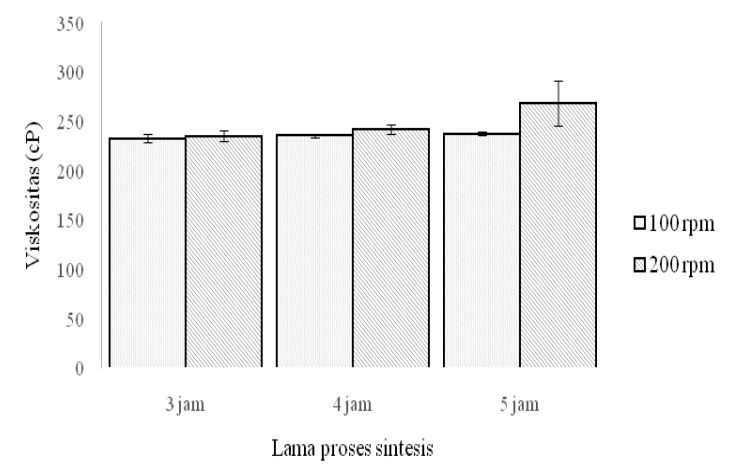

Gambar 4. Grafik hubungan antara lama proses sintesis pada berbagai tingkat kecepatan pengadukan terhadap viskositas surfaktan DEA yang dihasilkan

Hasil analisis ragam viskositas produksi surfaktan DEA tahap pertama menunjukan bahwa perlakuan kecepatan pengadukan memberikan pengaruh yang nyata terhadap viskositas surfaktan DEA yang dihasilkan sedangkan lama proses dan interaksinya pada proses sintesis surfaktan DEA tidak memberikan perbedaan yang nyata terhadap viskositas produk surfaktan DEA pada taraf $5 \%$. Viskositas surfaktan DEA yang dihasilkan berkisar antara $232,73-267,86 \mathrm{cP}$ pada suhu $30^{\circ} \mathrm{C}$. Surfaktan DEA yang dihasilkan memiliki warna kekuningan dan disimpan pada suhu ruang akan mengalami pemadatan. Surfaktan DEA yang diproduksi menggunakan kecepatan pengadukan 200 rpm 
memiliki viskositas lebih tinggi dibandingkan dengan kecepatan pengadukan $100 \mathrm{rpm}$.

\section{Densitas}

Densitas menunjukkan nilai massa per volume suatu bahan atau produk. Densitas pada penelitian ini diukur menggunakan alat density meter. Hasil uji densitas surfaktan DEA disajikan pada Gambar 5.

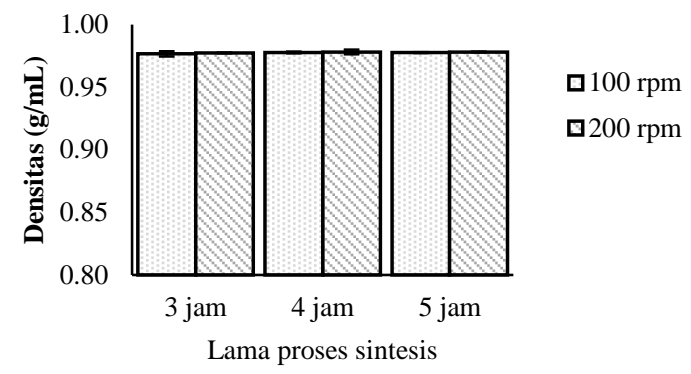

Gambar 5. Histogram pengaruh lama proses sintesis dan kecepatan pengadukan terhadap densitas surfaktan DEA yang dihasilkan

Hasil analisis keragaman densitas yaitu perlakuan lama proses dan kecepatan pengadukan maupun interaksi keduanya tidak memberikan pengaruh yang nyata terhadap densitas surfaktan DEA pada taraf $5 \%$. Nilai densitas yang dihasilkan berkisar antara 0,9772-0,9798 $\mathrm{g} / \mathrm{mL}$. Densitas surfaktan DEA yang dihasilkan tidak berbeda jauh dari surfaktan komersial yaitu cocodietanolamida yang memiliki nilai densitas $0,995 \mathrm{~g} / \mathrm{mL}$ yang dikeluarkan oleh Chem-Supply Pty Ltd. Hasil analisis keragaman densitas yaitu perlakuan lama proses dan kecepatan pengadukan maupun interaksi keduanya tidak memberikan pengaruh yang nyata terhadap densitas surfaktan DEA pada taraf 5\%. Nilai densitas yang dihasilkan berkisar antara 0,9772-0,9798 g/mL. Densitas surfaktan DEA yang dihasilkan tidak berbeda jauh dari surfaktan komersial yaitu cocodietanolamida yang memiliki nilai densitas $0,995 \mathrm{~g} / \mathrm{mL}$ yang dikeluarkan oleh Chem-Supply Pty Ltd.

\section{Pengujian $\mathrm{pH}$}

Pada pengujian $\mathrm{pH}$ larutan surfaktan DEA menunjukkan sifat larutan basa. Suatu larutan $\mathrm{pH}$ selain dipengaruhi oleh jenis zat yang terlarut dalam air pelarutnya, $\mathrm{pH}$ juga dipengaruhi oleh konsentrasi zat tersebut. Hasil pengujian $\mathrm{pH}$ surfaktan tahap pertama disajikan pada Gambar 6.

Hasil analisis ragam menunjukkan lama proses dan kecepatan pengadukan serta interaksi keduanya tidak menunjukkan perubahan yang signifikan terhadap $\mathrm{pH}$ surfaktan DEA pada taraf 5\%.Nilai pH yang dihasilkan berkisar antara 11,08 11,18 . Nilai $\mathrm{pH}$ surfaktan DEA yang dihasilkan cenderung bersifat basa. Nilai ini diduga disebabkan oleh unsur $\mathrm{N}$ yang terdapat pada produk surfaktan dietanolamida yang berasal dari senyawa dietanolamina yang bersifat basa dan juga dipengaruhi oleh katalis $\mathrm{NaOH}$ yang merupakan senyawa basa. Hasil analisis ragam pengaruh kondisi proses dan kecepatan pengadukan dari parameter yang digunakan dalam proses produksi surfaktan DEA didapatkan lama proses 4 jam dengan kecepatan pengadukan $100 \mathrm{rpm}$ menghasilkan surfaktan DEA terbaik.

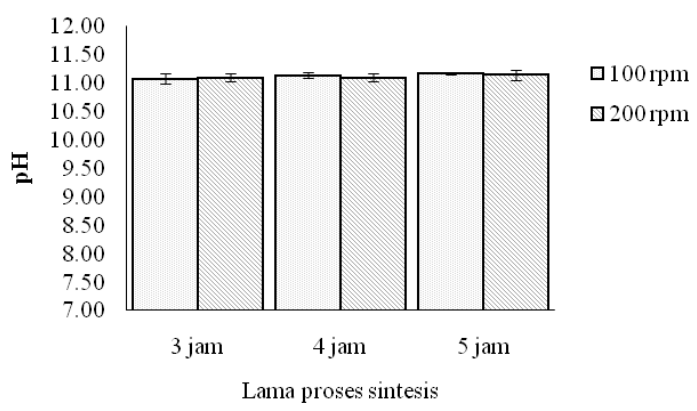

Gambar 6. Histogram pengaruh lama proses sintesis dan kecepatan pengadukan terhadap $\mathrm{pH}$ surfaktan DEA yang dihasilkan

\section{Pemilihan Jenis Pengaduk pada Proses Produksi Surfaktan DEA}

Hasil terbaik yang didapat pada perlakukan lama proses dan kecepatan pengadukan sintesis surfaktan DEA digunakan untuk sintesis surfaktan DEA pada tahap ini. Proses sintesis surfaktan DEA ini menggunakan reaktor yang dipasang baffle. Pada fluida yang memiliki kekentalan rendah, pengadukan tinggi akan menimbulkan cekungan permukaan media pada bagian tengah tangki yang disebut dengan vortex.Untuk mencegah terjadinya vortex maka dipasang bilah-bilah yang disebut sekat/baffle pada kedua sisi reaktor. Proses sintesis surfaktan DEA menggunakan 2 jenis pengaduk/impeller berupa propeller dan turbin.

Proses produksi pada tahapan ini menggunakan lama reaksi dan kecepatan pengadukan terbaik dari hasil analisis pada proses produksi surfaktan DEA sebelumnya. Lama reaksi yang digunakan adalah 4 jam dengan kecepatan pengadukan $100 \mathrm{rpm}$. Hasil pengujian proses produksi surfaktan DEA dengan menggunakan pengaduk propeller dan turbin disajikan pada Tabel 1.

Tabel 1. Hasil pengujian surfaktan DEA dengan perlakuan jenis pengaduk

\begin{tabular}{lccccc}
\hline Perlakuan & $\begin{array}{c}\text { Rendemen } \\
(\%)\end{array}$ & $\begin{array}{c}\text { Tegangan Permukaan } \\
(\mathbf{d y n e} / \mathbf{c m})\end{array}$ & $\begin{array}{c}\text { Viskositas } \\
(\mathbf{c P})\end{array}$ & $\begin{array}{c}\text { Densitas } \\
(\mathbf{g} / \mathbf{m L})\end{array}$ & $\mathbf{p H}$ \\
\hline Propeller & 95,25 & 14,28 & 245,41 & 0,973 & 11,05 \\
Turbin & 96,35 & 21,55 & 250,67 & 0,977 & 11,14 \\
\hline
\end{tabular}


Hasil analisis ragam proses produksi surfaktan DEA tahap ini menunjukkan jenis pengaduk propeller dan turbin tidak memberikan perbedaan yang nyata terhadap rendemen surfaktan DEA pada taraf 5\%. Hasil sintesis surfaktan DEA memiliki rendemen yang tidak berbeda dengan rendemen sintesis pada tahap pertama yaitu berkisar antara 96,35-95,24\%. Rendemen yang dihitung sama dengan rendemen pada produksi surfaktan DEA tahap pertama yaitu rendemen keseluruhan produk yang dihasilkan.

Tegangan permukaan suatu cairan merupakan tekanan yang bersifat internal yang dipengaruhi oleh daya tarik menarik molekul kearah bawah permukaan dari permukaan cairan. Molekul inilah yang menciptakan tekanan internal yang membatasi kecenderungan cairan untuk mengalir dan membentuk antarmuka yang besar dengan zat lain (Kamalakar et al., 2013). Tegangan permukaan yang dihasilkan pada tahap ini menunjukkan nilai tegangan permukaan yang lebih rendah. Penurunan nilai tegang permukaan berhubungan dengan surfaktan yang berpesan sebagai bahan aktif permukaan (Probowati et al., 2012).

Analisis ragam jenis pengaduk yang digunakan pada tahap ini menunjukkan perbedaan yang nyata terhadap tegangan permukaan surfaktan DEA pada taraf 5\%. Nilai tegangan permukaan yang dihasilkan dengan penggunaan jenis pengaduk propeller memiliki nilai lebih rendah yaitu 14,28 dyne/cm sedangkan produksi surfaktan DEA menggunakan jenis pengaduk turbin yaitu 21,55 dyne/cm. Sintesis tahap kedua ini menghasilkan surfaktan DEA yang lebih baik yang ditunjukkan oleh nilai tegangan permukaan yang lebih kecil dibandingkan tegangan permukaan surfaktan DEA pada tahap pertama. Dari hasil tegangan permukaan surfaktan DEA menunjukkan penggunaan pengaduk propeller menghasilkan nilai tegangan permukaan lebih rendah.

Viskositas sintesis surfaktan DEA tahap kedua yang dihasilkan tidak jauh berbeda masih dalam kisaran 200-300 cP. Ini menunjukkan perlakuan pada proses produksi surfaktan DEA tidak mempengaruhi kekentalan larutan surfaktan DEA. Analisis ragam menunjukkan bahwa jenis pengaduk propeller maupun turbin tidak memberikan perbedaan yang nyata terhadap viskositas surfaktan DEA pada taraf 5\%. Densitas produksi surfaktan
DEA pada tahap kedua menunjukkan nilai sedikit lebih rendah namun tidak begitu signifikan. Analisis ragam menunjukkan bahwa penggunaan sekat dan jenis pengaduk pada proses sintesis tidak memberikan pengaruh yang nyata terhadap densitas surfaktan DEA pada tahap kedua ini. Nilai densitas yang dihasilkan berkisar antara 0,973-0,977 g/mL. densitas surfaktan DEA tahap kedua ini tidak berbeda jauh dengan nilai densitas surfaktan DEA tahap pertama.

Nilai $\mathrm{pH}$ pada sintesis surfaktan DEA tahap kedua ini tetap cenderung bersifat basa. Nilai larutan surfaktan DEA yang dihasilkan berkisar pada $\mathrm{pH}$ \pm 11 . Dari hasil analisis ragam pada tahap pertama didapat nilai $\mathrm{pH}$ tidak dipengaruhi oleh lama proses reaksi, kecepatan reaksi surfaktan DEA maupun kombinasi keduanya, begitu juga dengan hasil analisis ragam pada tahap kedua ini. Nilai $\mathrm{pH}$ surfaktan DEA tahap kedua tidak dipengaruhi oleh jenis pengaduk yang digunakan pada reaktor surfaktan DEA. Pada penelitian Nurminah (2005) menunjukkan $\mathrm{pH}$ yang dihasilkan dipengaruhi oleh suhu reaksi dietanolamina dan juga jumlah mol dietanolamina.

Warna produk surfaktan DEA yang dihasilkan adalah berwarna kuning kecoklatan (Gambar 7). Minyak nabati yang diproses dengan pemanasan suhu tinggi dalam jangka waktu yang lama dapat menyebabkan kerusakan minyak akibat oksidasi termal yang ditandai dengan perubahan warna dan bau. Surfaktan DEA pada penelitian ini diproses dengan suhu tinggi sekitar $140^{\circ} \mathrm{C}$ dengan lama proses palingsingkat adalah 3 jam, inilah yang menyebabkan warna surfaktan DEA yang dihasilkan menjadi kuning kecoklatan

Kondisi proses surfaktan DEA terbaik pada penelitian ini didapatkan pada lama reaksi 4 jam dengan kecepatan pengadukan $100 \mathrm{rpm}$ dan menggunakan baffle pada kedua sisi reaktor serta menggunakan jenis pengaduk propeller. Menurut Flider (2001) yang menjadi bahan baku surfaktan adalah bentuk oleokimia dasar sehingga minyak dan lemak harus diproses terlebih dahulu. Hasil oleokimia dasar yang dihasilkan berupa asam lemak, gliserol, metil ester dan fatty alcohol.Produk surfaktan DEA terbaik ini selanjutnya dibandingkan dengan cocodietanolamida komersial. Hasil perbandingan disajikan pada Tabel 2

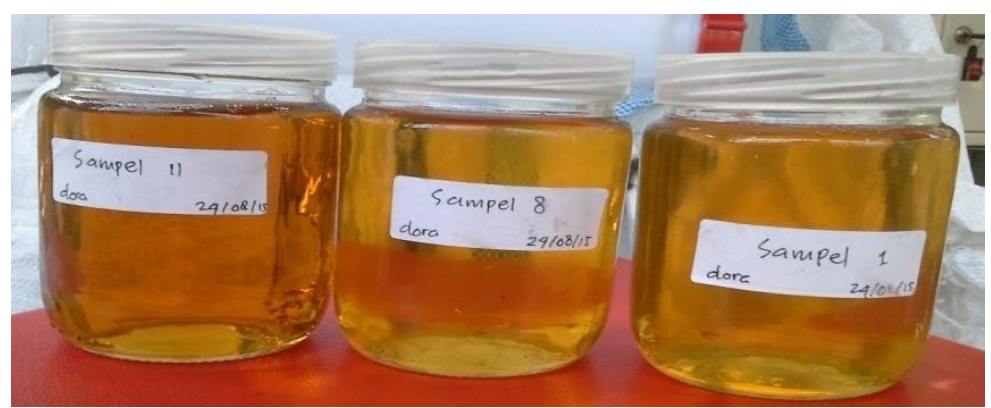

Gambar 7. Contoh hasil produksi surfaktan DEA 
Tabel 2. Perbandingan beberapa karakteristik Dietanolamida hasil penelitian terbaik dibandingkan dengan cocodietanolamida komersial

\begin{tabular}{lcc}
\hline \multicolumn{1}{c}{ Karakteristik } & Dietanolamida terbaik & $\begin{array}{c}\text { Cocodietanolamida } \\
\text { komersial }\end{array}$ \\
\hline Bobot jenis $(\mathrm{g} / \mathrm{mL})$ & 0,97 & 0,98 \\
Derajat keasamaan $(\mathrm{pH})$ & 11,1 & 10,85 \\
Tegangan permukaan $(\mathrm{dyne} / \mathrm{cm})$ & 14,28 & 41,37 \\
kekeruhan dalam air $(\mathrm{NTU})$ & 410 & 176 \\
\hline
\end{tabular}

Bobot jenis dan derajat keasaman $(\mathrm{pH})$ yang dihasilkan dari kedua jenis surfaktan DEA ini tidak berbeda jauh namun nilai tegangan permukaan dan kekeruhannya berbeda jauh. Dari hasil perbandingan dapat dilihat bahwa dietanolamida hasil penelitian mampu menurunkan nilai tegangan permukaan air dari 72 dyne/cm menjadi 14.28 dyne/cm sedangkan cocodietanolamida komersial hanya mampu menurunkan tegangan permukaan air menjadi 41.37 dyne $/ \mathrm{cm}$. ini menunjukkan bahwa dietanolamida terbaik hasil penelitian memiliki kemampuan lebih besar dalam menurunkan tegangan permukaan air. Dilihat dari warna surfaktan DEA didalam air, dietanolamida terbaik hasil penelitian memiliki nilai kekeruhan yang tinggi yaitu 410 NTU dibandingkan cocodietanolamida komersial yaitu 176 NTU. Nilai ini menunjukkan bahwa dietanolamida terbaik hasil penelitian menghasilkan larutan yang lebih keruh didalam air dibandingkan cocodietanolamida komersial.

\section{KESIMPULAN}

\section{Kesimpulan}

Proses sintesis surfaktan DEA pada reaktor $25 \mathrm{~L} /$ batch pada penelitian tahap pertama yaitu lama proses dan kecepatan pengadukan menunjukkan proses sintesis surfaktan DEA terbaik adalah proses produksi dengan lama proses 4 jam dan kecepatan pengadukan $100 \mathrm{rpm}$ serta penelitian pada tahap selanjutnya dengan penentuan jenis pengaduk menunjukkan surfaktan DEA terbaik menggunakan jenis pengaduk propeller dengan nilai tegangan permukaan surfaktan DEA pada proses tersebut adalah 14,28 dyne/cm, rendemen 95,24\%, viskositas $245,41 \mathrm{cP}$, densitas $0,973 \mathrm{gr} / \mathrm{mL}$ dan nilai $\mathrm{pH} 11,1$.

\section{DAFTAR PUSTAKA}

Ferdinan MA, Hambali E, Rahayuningsih M. 2016. Studi perbandingan produk insektisida formulasi EC (Emulsifiable Concentrate) dengan penambahan surfaktan dietanolamida menggunakan vortex, mixer dan homogenizer. Jurnal Teknologi Industri Pertanian. 26(1): 60-67.
Flider FJ. 2001. Commercial considerations and markets for naturally derived biodegradable surfactants. INFORM 12(12):1161-1164.

Geankoplis CJ. 2003. Transport Process And Separation Process Principles. Ed ke-4. Indiana (US): Prentice Hall.

Hambali E, Bunasor TK, Suryani A, Kusumah GA. 2005. Aplikasi Dietanolamida dari asam laurat minyak inti sawit pada pembuatan sabun transparan. Jurnal Teknologi Industri Pertanian. 15(2): 46-53.

Hambali E, Suryani A, Rivai M, Sutanto AI, Nisya FN, Nurkania A. 2013. Pengembangan teknologi proses produksi surfaktan Dietanolamida (DEA) dari metil ester olein sawit dan aplikasinya untuk personal care products. [laporan akhir penelitian untuk Kementerian Perindustrian]. Bogor: Institut Pertanian Bogor.

Hasenhuetti GH. 2000. Design and application of fat-basedsurfactant. Di dalam: introduction to fats and oil technology. $2^{\text {nd }}$ edition. Editors: O'Brien RD, WE Farr dan PJ wan. IIIinois (US): AOCS Press

Kamalakar K, Tenneti S, Yarra M, Rachapudi BNP, Mallapalli SLK. 2013. Synthesis of thumba, castor and sal fatty ethanolamide-based anionic surfactant. Journal of Surfactant and Detergents. 17(4): 637-645.

Nurminah M. 2005. Kajian pengaruh mol reaktan, suhu dan lama reaksi dalam pembuatan surfaktan dietanolamida dari metil ester dominan C12 minyak inti sawit [tesis]. Bogor: Institut Pertanian Bogor.

Probowati A, Paradigma CG, Diyono I. 2012. Pembuatan surfaktan dari minyak kelapa murni (VCO) melalui proses amidasi dengan katalis $\mathrm{NaOH}$. Jurnal Teknik Kimia Indonesia. 1(1): 424-432.

Susanto AI. 2007. Sintesis metil ester sulfonat dari metil ester berbahan baku PKO pada skala pilot plant. [tesis]. Bogor (ID): IPB. 